\title{
Avaliação do efeito de borda da Reserva Biológica de Pindorama, SP
}

\section{Edge effect evaluation of Pindorama Biological Reserve-SP}

\author{
Maria Teresa Vilela Nogueira Abdo ${ }^{1}$; Sergio Valiengo Valeri ${ }^{2}$; Antonio Sergio Ferraudo ${ }^{3}$
}

\begin{abstract}
Resumo: Avaliação do efeito de borda em dois fragmentos da Reserva Biológica de Pindorama, SP, em 65 parcelas de 400 m², determinando o grau de infestação na parcela, distância da borda, altura, área basal e grau de infestação das quatro maiores árvores. Num quadrante sorteado se determinou atributos de solo e altitude, número de espécies, número, área basal e altura dos indivíduos arbóreos com DAP $\geq$ a $5 \mathrm{~cm}$ e os descritores fitossociológicos: densidades absoluta e relativa (DAi e DRi), dominâncias relativa (DoR), freqüências absoluta e relativa (FAi e FR), valor de importância (VI), índice de diversidade de espécies (H'), coeficiente de equabilidade (J) e índice de similaridade (ISJ). O agrupamento hierárquico dividiu as parcelas em dois grupos com valores médios de H'e J e valor de ISJ entre eles. O teste de k-médias e componentes principais caracterizaram parcelas semelhantes cujas variáveis com maior poder de discriminação foram: altura das quatro maiores árvores, número de indivíduos por parcelas, área basal total, infestação por parcelas, número de espécies. No Grupo 2 mais perto da borda houve maior infestação de plantas invasoras e lianas nas quatro maiores árvores com 31,75\% das parcelas sob efeito de borda e o Grupo 1 apresentou 22,22\% .
\end{abstract}

Palavras-chaves: Floresta estacional semidecidual, análise multivariada, floresta tropical atlântica, fragmentos florestais.

Abstract: Edge effect evaluation in two forest remnants in the Biological Reserve Pindorama, SP, in 65 plots of $400 \mathrm{~m}^{2}$, using data of: degree of infestation in the plot, distance from edge, height, basal area and degree of infestation of the four largest trees. In a random quadrant were evaluated soil and altitude, species number, number, basal area and height of trees with diameter at breast height $(\mathrm{DBH}) \geq 5 \mathrm{~cm}$ and phytosociological describers: density absolute and relative, relative dominancy, frequency relative and absolute, importance value, species diversity index $\left(\mathrm{H}^{\prime}\right)$, evenness coefficient $(\mathrm{J})$ and similarity index (ISJ). The hierarchical clustering gathered parcels into two groups with specific values of the variables H' an J and ISJ between them. The k-means and principal components analyses characterized similar plots groups and the variables with greater power of discrimination were: height of the four largest trees, number of individuals in plots, total basal area, infestation in plots, number of species. Group 2, closer to the edge had higher infestation of weeds and vines in the four largest trees $31,75 \%$ plots under edge effect and Group 1 had a lower percentage of plots under edge effect $(22.22 \%)$.

Key words: Seasonal semideciduous forest, multivariated analysys, atlantic tropical forest, forest remnants

\footnotetext{
*Autor para correspondência

Recebido para publicação em 06/05/2015; aprovado em 15/08/2015

${ }^{1}$ Dra. Pesq Cíentífica nível IV, Polo Centro Norte - APTA(Agencia Paulista de Tecnologia do Agronegócio), Pindorama, SP, Tel: (17) 35721592. E-mail: mtvilela@terra.com.br, mtvilela@apta.sp.gov.br

${ }^{2}$ Dr. Professor Titular do Departamento de Produção Vegetal, FCAV-UNESP, Campus de Jaboticabal, SP. Tel (16) 32092668. E-mail: valeri@ fcav.unesp.br ${ }^{3}$ Dr.Professor Assistente Doutor do Departamento de Ciências Exatas, FCAV- UNESP, Campus de Jaboticabal, SP. Tel: (16) 3209 2624. E-mail: fsajago@gmail.com
} 


\section{INTRODUÇÃO}

Segundo Viana (1990), fragmento florestal é uma área de vegetação natural contínua, interrompida por barreiras que são capazes de diminuir o fluxo de animais, pólen e sementes. Essas barreiras podem ser de origem antrópica como estradas, culturas agrícolas e cidades ou de origem natural como lagos, rios e outras formações vegetais.

A estrutura de fragmentos florestais está relacionada com a ocorrência dos indivíduos arbóreos de diferentes grupos sucessionais, onde esses grupos são definidos de acordo com as exigências edáficas das espécies, principalmente a exigência de luz (JARDIM et al., 1996; LEITÃO FILHO, 1993; SWAINE; WHITMORE 1998).

Para Viana (1990) o histórico de perturbação e forma da área, tipo da vizinhança e o grau de isolamento podem interferir de forma decisiva na estrutura e dinâmica de um fragmento. Para o autor, fragmentos capazes de perpetuar a dinâmica sucessional natural ao longo do tempo sem interferência humana são autossustentáveis.

A abertura de clareiras pode contribuir para a diversidade dos fragmentos, pois algumas espécies dependem desses sítios para regeneração, como é o caso das espécies pioneiras (TABARELLI; MANTOVANI, 1999). A riqueza de espécies pioneiras varia com o bioma, o local e a presença de plantas invasoras. Os autores determinaram que a densidade e diversidade de espécies pioneiras apresentaram relações negativas com a altura do dossel adjacente e infestação de bambu uma vez que esses fatores funcionam como barreiras à chegada de luz direta à superfície

Além do processo natural de sucessão, o efeito de borda é um fator que afeta o fragmento (TABANEZ et al., 1997) e consiste na alteração de variáveis físicas, químicas e biológicas na faixa marginal dos fragmentos (LIMARIBEIRO, 2008) que acarretam numa modificação da ocorrência de espécies. Essas alterações são resultantes da pressão que o meio externo exerce sobre os fragmentos e sua intensidade varia de acordo com a natureza das atividades na área em torno do fragmento.

De acordo com Tabanez et al. (1997), o efeito de borda interfere na ocorrência de espécies pioneiras, secundárias e climácicas em uma faixa que pode chegar até 100 metros de extensão. Nessas faixas, a ocorrência de espécies invasoras é favorecida pela presença de luz e atributos de solos (TABARELLI; MANTOVANI, 1999).

Estudos e inventários que forneçam dados sobre a vegetação e ocorrência de indivíduos arbóreos em um determinado local, são de grande valia para trabalhos de preservação e recuperação de fragmentos florestais, uma vez que fornecem um panorama do grau de degradação em que a área abordada se encontra e a ocorrência de efeito de borda.

Ante o exposto, o presente trabalho teve como objetivo caracterizar populações de espécies arbóreas, com base nos atributos da vegetação e distanciamento da borda em dois fragmentos de Floresta Estacional Semidecidual, circundados por área de culturas agrícolas da Reserva Biológica de Pindorama, SP.

\section{MATERIAL E MÉTODOS}

\section{Caracterização da Área}

$\mathrm{O}$ estudo foi realizado em dois fragmentos de Floresta Estacional Semidecidual da Reserva Biológica de Pindorama-
SP, pertencentes ao Polo Regional de Desenvolvimento Regional do Centro Norte, ligadas a Agencia Paulista de Tecnologia dos Agronegócios (APTA) que possui uma área total de 532,8 ha. Aproximadamente 120 ha de mata remanescente dividida em quatro fragmentos desse total constituem a Reserva Biológica criada pela Lei no ${ }^{\circ} 4960$ de 06 de janeiro de 1986. A vegetação local é caracterizada como o bioma Mata Atlântica e classificada como Floresta Latifoliada Tropical Estacional Semidecidual.

Segundo Lepsch \& Valadares (1976), o referido Polo está localizado entre as coordenadas $48^{\circ} 55^{\prime} \mathrm{W}$ e $21^{\circ} 13^{\prime} \mathrm{S}$. A altitude varia de 498 a 594 metros. O relevo é ondulado nas partes de altitudes maiores, passando a suave-ondulado nas altitudes menores. A maior parte dos declives está compreendida entre $2 \%$ e $10 \%$. Conforme a classificação de Köppen, o clima enquadra-se no tipo AW, definido como tropical úmido com estação chuvosa no verão e seca no inverno. A precipitação média anual é de $1258 \mathrm{~mm}$, a temperatura média dos três meses de verão é $23,8{ }^{\circ} \mathrm{C}$, e a média dos meses de inverno é de $19,3{ }^{\circ} \mathrm{C}$. De acordo com o levantamento pedológico detalhado do Polo realizado por Lepsch \& Valadares (1976) os solos do local do experimento foram classificados conforme a COMISSÃO NACIONAL DE SOLOS (1960), como Solos Podzolizados Lins- Marília, variação Marília. Pela classificação de solos da EMBRAPA (2006), esses solos são classificados atualmente como Argissolos de textura arenosa média/abrupto. $\mathrm{Na}$ área do Polo Norte centro foram classificadas seis unidades de solos com características de diferenciação distintas. Duas unidades de solos são similares, a Pindorama e a Serrinha, constituídas de solos eutróficos profundos e bem desenvolvidos, bem drenados, com alta saturação por bases, diferenciando-se apenas na espessura do horizonte A. Na unidade Pindorama, a espessura do horizonte A pode chegar a $1 \mathrm{~m}$. É nessa unidade que está localizada a topossequência denominada Área 1. A unidade Concreção é composta de solos moderadamente profundos, moderadamente drenados e moderadamente desenvolvidos, apresentando uma diferenciação marcante em relação às outras duas unidades que é o valor da saturação por base em torno de $50 \%$ nos horizontes A e B21 e espessura do horizonte A em torno de $50 \mathrm{~cm}$. Nesta unidade Concreção está localizada a topossequência denominada Área 2.

\section{Demarcação das Parcelas}

As parcelas foram distribuídas ao longo de dois transectos 1 e 2 (Figura 1), com base em (TABANEZ et al., 1997). Para cada topossequência foram demarcadas parcelas sequenciais de $20 \mathrm{~m}$ x $20 \mathrm{~m}$. Na topossequência 1 foram demarcadas 43 parcelas e, na topossequência 2, 22 parcelas. Em cada parcela de $400 \mathrm{~m} 2$ foi sorteado um quadrante de 10 m x 10 m para caracterização de indivíduos arbóreos com diâmetro a altura do peito (DAP) $\geq 5 \mathrm{~cm}$, para o levantamento fitossociológico. O tamanho das parcelas amostradas foi avaliado quanto à suficiência amostral com base na curva da relação espécie/aérea de acordo com (MUELLERDOMBOIS; ELLENBERG, 1974). O levantamento fitossociológico e a coleta de material para análise de solos foram realizados no quadrante sorteado de cada parcela $(10 \mathrm{~m}$ X $10 \mathrm{~m}$ ). Para a avaliação do grau de infestação da parcela por plantas invasoras, avaliação da área basal, altura e infestação por lianas das quatro maiores árvores foram considerada a parcela total de $20 \mathrm{~m}$ x $20 \mathrm{~m}$. 


\section{Coleta e Avaliação de Solos}

Para a análise física e química do solo foram retiradas, para cada parcela, amostras compostas de 20 subamostras dentro do quadrante sorteado $\left(100 \mathrm{~m}^{2}\right)$, usando trado holandês, a uma profundidade de $0-20 \mathrm{~cm}$. As amostras, acondicionadas em sacos de plástico, foram encaminhadas para o laboratório. Após secagem ao ar e obtenção da terra fina seca ao ar, foram realizadas as seguintes análises: granulometria, pelo método do densímetro; $\mathrm{pH}$ em $\mathrm{CaCl} 2$ (mol L-1); matéria orgânica (MO); fósforo, potássio, cálcio e magnésio, pelo método de resina trocadora de íons; acidez potencial $(\mathrm{H}+\mathrm{Al})$, pelo método do acetato de cálcio $1 \mathrm{~mol} \mathrm{L-1}$. A saturação por bases (V\%) foi obtida por cálculo (RAIJ et al., 1996).

\section{Levantamento Fitossociológico}

No quadrante sorteado de $100 \mathrm{~m}^{2}$, foram identificados os indivíduos arbóreos vivos com DAP (diâmetro a altura do peito a $1,30 \mathrm{~cm}$ do solo) $\geq 5 \mathrm{~cm}$. Esses indivíduos foram identificados com placas de metal constando o número de identificação da parcela e do indivíduo. Para cada individuo amostrado foi anotado o diâmetro e coletado material botânico para identificação. O material foi herborizado e a identificação feita por meio de chaves de identificação e comparação com exsicatas no Horto da UNESP- Campus de São José do Rio Preto Campus Jaboticabal

Para a vegetação levantada em cada fragmento foram calculados os seguintes descritores fitossociológicos: densidade absoluta $(\mathrm{DAi})=\mathrm{Ni} / \mathrm{A}$; densidade relativa $(\mathrm{DRi})=$ $100 \mathrm{Ni} / \mathrm{N}$; dominância relativa $(\mathrm{DoR})=(\mathrm{ABi} / \mathrm{ABt}) 100$; frequência absoluta da espécie $(\mathrm{FAi})=100 *(\mathrm{pi} / \mathrm{P})$; frequência relativa $(\mathrm{FR})=100 *(\mathrm{FAi} / \Sigma \mathrm{FA})$; valor de importância $(\mathrm{VI})=(\mathrm{DRi}+\mathrm{DoR}+\mathrm{FR})$. Onde, $\mathrm{Ni}=$ número de indivíduos da espécie, $\mathrm{A}$ = área total levantada, $\mathrm{N}$ = número de indivíduos total do levantamento, $\mathrm{ABi}$ = área basal de todos os indivíduos da espécie e, $\mathrm{ABt}=$ área basal de todos os indivíduos identificados, $\mathrm{Pi}=$ número de parcelas em que a espécie " i” e foi encontrada e P é o número total de parcelas de $10 \mathrm{~m}$ x10 m. Para a análise da diversidade das espécies arbóreas do fragmento florestal, foram calculados o Índice de Diversidade de Shannon (H') e o Coeficiente de Equabilidade de Pielou (J)

$\mathrm{H}^{\prime}=$ Pi ln $\mathrm{Pi}$ ) onde: Pi é o número de indivíduos da espécie i / Número total de indivíduos, ln é logaritmo neperiano; H'max= ln Ne e $\mathbf{J}=\mathrm{H}^{\prime} / \mathrm{H}^{\prime} \max$. . Para verificar a similaridade entre as áreas foi calculado o Índice de Similaridade de Jaccard (ISJ) pela fórmula: ISJ $=\mathrm{c} /(\mathrm{a}+\mathrm{b}-\mathrm{c})$ onde $\mathrm{a}=$ número de espécies das áreas $\mathrm{A}, \mathrm{b}=$ número de espécies da área $\mathrm{B}$ e c= número de espécies comuns entre a área A e B.

A caracterização da vegetação foi feita inicialmente com análise multivariada de agrupamento hierárquico pelo método Ward, processada com os atributos físicos e químicos do solo que possibilitou a divisão em cinco grupos de parcelas e posteriormente foram recalculados os descritores fitossociológicos para cada grupo que geraram os centróides para cada grupo de parcelas originado do dendrograma.

\section{Avaliação do Grau de Infestação em Cada Parcela}

Tomando-se a área total das parcelas de $20 \mathrm{~m}$ x $20 \mathrm{~m}$ cada parcela avaliada foi feita uma avaliação quanto ao grau de infestação por plantas invasoras. Foram criadas 10 classes de infestação com base em Valeri et al. (2003) que variaram de nula (0) a completamente infestada (10) onde a pontuação foi dada de acordo com uma avaliação da porcentagem de cobertura da área por lianas e outras plantas rasteiras indesejadas. Adicionalmente foram anotadas todas as plantas consideradas invasoras em cada parcela, como: lianas, bambu, capim colonião, cana de açúcar e assim por diante. Esses dados fizeram parte da caracterização de cada parcela e foram avaliados junto com os atributos de solos quanto a uma possível correlação com a ocorrência de determinadas espécies.

\section{Avaliação das Quatro Maiores Árvores de Cada Parcela}

Foram demarcadas e identificadas as quatro maiores árvores tomando como unidade amostral a área total das parcelas de $20 \mathrm{~m}$ x $20 \mathrm{~m}$. Essa avaliação está de acordo com o conceito de altura dominante, onde são avaliadas 100 árvores por hectare (BURGER, 1974). Tomando-se a área amostral de $400 \mathrm{~m}^{2}$ obtém o número amostra de 4 maiores árvores por parcela.

Cada árvore foi identificada e foram medidas o DAP, altura e grau de infestação por lianas e distanciamento da borda. Para avaliara o grau de infestação das árvores por cipós foram criadas 10 classes de infestação conforme Valeri et al. (2003) que variaram de nula (zero) a completamente infestada (dez) A pontuação foi dada de acordo com uma avaliação da porcentagem de cobertura das árvores por lianas e outras plantas. Esses dados entraram na caracterização de cada parcela e foram avaliados junto com os atributos de solos quanto.

\section{Análise Estatística}

Com a finalidade de verificar as semelhanças entre parcelas, foram usados os atributos de vegetação de cada parcela: grau de infestação, distanciamento da borda, número de espécie, número de indivíduos, área basal total e altura média de todos os indivíduos arbóreos com DAP $\geq 5 \mathrm{~cm}$ amostrados em um quadrante sorteado de $100 \mathrm{~m}^{2} \mathrm{e}$ área basal total, altura média e grau de infestação por lianas das quatro maiores árvores da área total da parcela $400 \mathrm{~m}^{2}$. Considerando-se a estrutura multivariada contida nos dados, foram utilizadas técnicas estatísticas exploratórias para verificar semelhanças entre parcelas na tentativa de agrupálas, usando-se os atributos de vegetação e distanciamento da borda. A análise multivariada de agrupamento pelo método hierárquico foi processada usando a distância euclidiana como medida de semelhança e o método de Ward, como algoritmo de ligação entre os grupos numa tentativa de avaliar a estrutura de grupos existentes buscando adotar uma quantidade de grupos para em complemento analisar também por abordagem de agrupamento envolvendo métodos não hierárquicos. Aqui se usou o algoritmo k-means (HAIR et al., 2005), cujos passos estão descritos a seguir:

a) escolher $\mathrm{k}$ distintos valores iniciais para centros dos grupos. Podem ser utilizadas $\mathrm{k}$ sementes aleatórias para assumir cada centro inicial dos grupos, ou pode-se usar uma pequena parte dos dados para calcular centros iniciais dos grupos;

b) associar cada ponto ao centro mais próximo;

c) recalcular o centro de cada grupo;

d) repetir os itens a e b até não haver alterações.

Ainda, buscando discriminar amostras com padrões diferenciados, aplicou-se aos dados, a análise de componentes principais (ACP) que é uma técnica que cria variáveis latentes 
ortogonais, com centro na região de maior concentração da variabilidade. Para isso, foi utilizada a matriz de covariância dos dados, da qual foram extraídos os autovalores que originam os autovetores (componentes principais), que são combinações lineares das variáveis originais. A dispersão das unidades experimentais passa a ser representada pelos auto vetores construídos com os maiores autovalores, pois preservam maior quantidade da informação original.

Segundo o critério de Kaiser, foram considerados os autovalores acima de um (1), pois geram componentes com quantidade relevante de informação contida nas variáveis originais.Foi avaliado o poder discriminatório de cada variável pela fórmula:

$$
\mathrm{r}_{\mathrm{x}_{\mathrm{j}}}\left(\mathrm{cp}_{\mathrm{h}}\right)=\frac{\mathrm{a}_{\mathrm{jh}} \sqrt{\lambda_{\mathrm{h}}}}{\mathrm{s}_{\mathrm{j}}}
$$

Figura1- Dendrograma com estrutura de grupos contida no conjunto das parcelas baseada em atributos da vegetação de duas topos sequências de Floresta Tropical na Reserva Biológica de Pindorama, SP, Brasil.

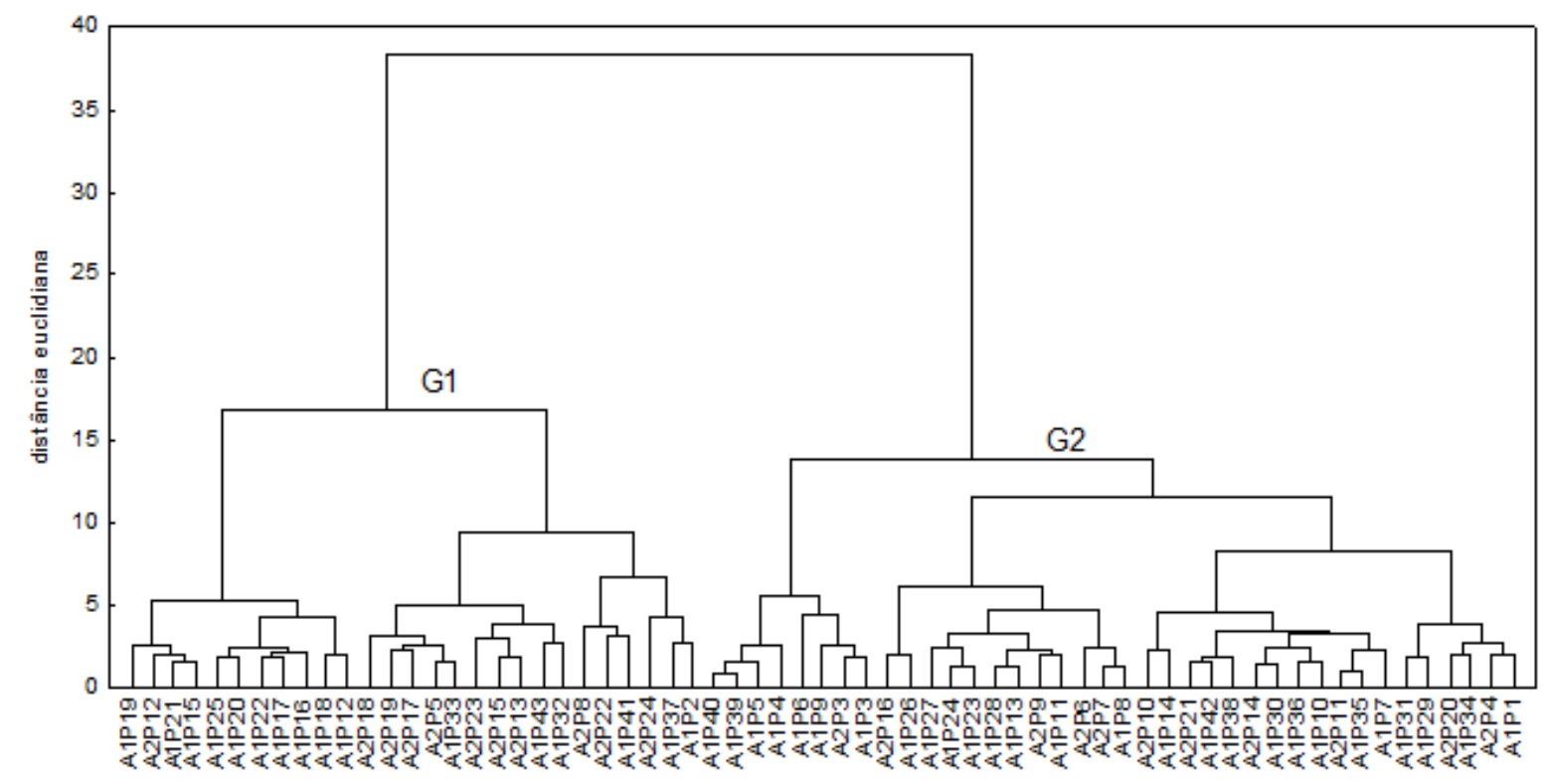

Vê-se nitidamente uma divisão dos dados em 2 grupos quanto à características da vegetação das parcelas. A partir da divisão em dois grupos foram obtidos os valores médios de altitude e dos atributos físicos e químicos de solo para cada grupo (Tabela 1).

Tabela 1: Média dos atributos físicos e químicos do solo por grupos de parcelas (G1 e G2).

\begin{tabular}{|c|c|c|c|c|c|c|c|c|c|c|}
\hline \multirow{2}{*}{$\begin{array}{r}\text { Grupo } \\
\text { G1 }\end{array}$} & $\begin{array}{r}\text { Argila } \\
\quad \ldots . . . \mathrm{g}\end{array}$ & $\begin{array}{l}\text { Areia } \\
1 \\
1 \ldots \ldots .\end{array}$ & \multirow{2}{*}{\begin{tabular}{c}
\multicolumn{1}{c}{\begin{tabular}{c}
\multicolumn{1}{c}{} \\
$\mathrm{mg} \mathrm{dm}^{-3}$
\end{tabular}} \\
5,77
\end{tabular}} & \multirow{2}{*}{$\begin{array}{l}p H \\
\mathrm{Ca} \mathrm{Cl}_{2} \\
6,04\end{array}$} & \multirow{2}{*}{$\begin{array}{c}\begin{array}{c}M O \\
\mathrm{~g} \mathrm{dm}^{-3}\end{array} \\
26,25\end{array}$} & \multirow{2}{*}{$\begin{array}{c}K^{+} \\
2,50\end{array}$} & \multicolumn{2}{|c|}{$\begin{array}{cc}\mathrm{Ca}^{2+} & \mathrm{Mg}^{2+} \\
\ldots \ldots \ldots \ldots \ldots \ldots \mathrm{mol}_{\mathrm{c}} \mathrm{dm}^{-3}\end{array}$} & \multicolumn{2}{|c|}{$\begin{array}{l}H+A l \\
\ldots \ldots \ldots \ldots \%\end{array}$} \\
\hline & 143,66 & 778,07 & & & & & 57,44 & 14,55 & 15,48 & 81,845 \\
\hline $\mathrm{G} 2$ & 145,81 & 770,81 & 6,10 & 6,02 & 25,78 & 2,22 & 60,02 & 13,13 & 14,97 & 82,61 \\
\hline
\end{tabular}

Tabela 2. Média das características das quatro maiores árvores por grupo de parcelas, infestação da parcela (IF), distancia da borda (DB), altura $(\mathrm{H})$. área basal(Na) e infestação das quatro maiores árvores na parcela (IF4 mai)

\begin{tabular}{cccccc}
\hline Grupo & IF & DB & H4 mai & Ab4 mai & IF4 mai \\
\hline G1 & 4,07 & 205,46 & 18,53 & 14,72 & 4,65 \\
G2 & 7,29 & 172,68 & 12,57 & 9,81 & 5,73 \\
\hline
\end{tabular}

Após a obtenção das médias foram recalculados os seguintes descritores fitossociológicos para cada grupo: número de espécies, número de indivíduos por hectare, área basal por hectare de todos os indivíduos, valor de importância, Índice de Shannon (H') e Índice de Equabilidade em que rxj $(\mathrm{CPh})$ é a correlação entre a variável xj e o componente principal $\mathrm{cph}$, ajh é o coeficiente da variável j no

A percentagem da variância total contida em cada componente $\mathrm{CPh}$ foi obtida segundo a fórmula: $\quad \mathrm{CP}_{\mathrm{h}}=\frac{\lambda_{\mathrm{h}}}{\mathrm{T}(\mathrm{C})} 100$ $(\lambda 1+\lambda 2+\ldots+\lambda h)$.

\section{RESULTADOS E DISCUSSÃO}

Caracterização do Solo e da Vegetação

A estrutura de grupos obtida consta no dendrograma da Figura 1. matriz de variância. das quatro maiores árvores por grupo adotado de parcelas (Tabela2).

de Pielou (J) da comunidade arbóreas, bem como o grau de infestação de plantas invasoras (Tabela 3). 
Tabela 3: Altitude (A), infestação por parcela (IF), distância da borda(DB), número de espécies (Ne ha ${ }^{-1}$ ) por ha, de indivíduos por hectare (Ni ha-1), área basal total (Abt), altura média (hmed), índices de diversidade (H') e equabilidade (J) das espécies arbóreas (DAP $\geq 5 \mathrm{~cm}$ ) por grupos de parcelas.

\begin{tabular}{cccccccccc}
\hline $\mathrm{G}$ & $\mathrm{A}(\mathrm{m})$ & $\mathrm{IF}$ & $\mathrm{DB}$ & $\mathrm{Ne} \mathrm{ha}^{-1}$ & $\mathrm{Ni} \mathrm{ha}^{1}$ & $\mathrm{Abt}$ & Hméd & $\mathrm{H}^{\prime}$ & $\mathrm{J}$ \\
\hline $\mathrm{G} 1$ & 561,9 & 4,07 & 205,4 & 60 & 11,03 & 7,3 & 10,8 & 3,48 & 0,85 \\
$\mathrm{G} 2$ & 568,3 & 7,29 & 172,6 & 58 & 7,07 & 4,4 & 7,5 & 3,55 & 0,86 \\
\hline
\end{tabular}

Os valores de H' encontrado nos grupos de parcelas mostram que os dois fragmentos avaliados apresentam uma diversidade de espécies média já que estão superiores aos valores apresentados em estudos realizados nos Estado de São Paulo por Nóbrega et al. (2007) em Luiz Antônio e por Durigan et al.(2000) na região de Gália. Os valores de H'estão muito próximos dos maiores valores de H' obtidos para Mata Atlântica (LEITÃO FILHO, 1987).

No Grupo 1 de parcelas, observa-se um distancia média da borda de 205,46 m e no Grupo 2 a distância média é de 172,68 m. No Grupo $122,22 \%$ das parcelas estão sob efeito de borda pois estão localizadas a menos de $100 \mathrm{~m}$ da bordadura do fragmento. No Grupo 2, a porcentagem de parcelas nessa condição, sob efeito de borda, aumenta para $31,57 \%$. Essa situação pode ser observada pelos valores de infestação da parcela onde no grupo 1 o grau de infestação da área das parcelas recebeu um valor menor de 4,07 e no Grupo 2 esse valor sobe para 7,29 indicando maior presença de vegetação infestante não arbórea.

Pode-se observar uma relação inversa entre a altura do dossel e infestação da parcela por plantas não arbóreas onde o Grupo 1 com altura médias das árvores de 10,8 m apresentou uma infestação da parcela de 4,07 e o Grupo 2 com uma altura média de 7,5 m apresentou uma infestação da parcela de 7,29 provavelmente pela maior disponibilidade de luz. Esses dados estão de acordo com experimento realizado por Tabarelli \& Mantovani (1999) que observaram parcelas com espécies arbóreas mais altas apresentaram menor infestação por bambu.

Adotando-se como dois a quantidade de grupos para estudo aplicou-se a análise de agrupamento pelo método não hierárquico empregando o algoritmo K-means cujos perfis dos grupos constam da Figura 2.

Figura 2. Médias das variáveis: $\mathrm{N}$ esp= número de espécie por parcela, $\mathrm{N}$ ind = número de indivíduos por parcela, $\mathrm{Ab}$ total= área basal total por parcela, $\mathrm{H}$ média= altura média de todos indivíduos por pacela, Inf parc= grau de infestação por parcela, Dist bord= distância da parcela da borda, $\mathrm{H} 4$ mai= altura média das 4 maiores árvores da parcela, Ab 4 mai= área basal das quatro maiores árvores da parcela, Inf 4 mai= infestação média das quatro maiores árvores para os três grupos formados pelo método $\mathrm{k}$ médias.

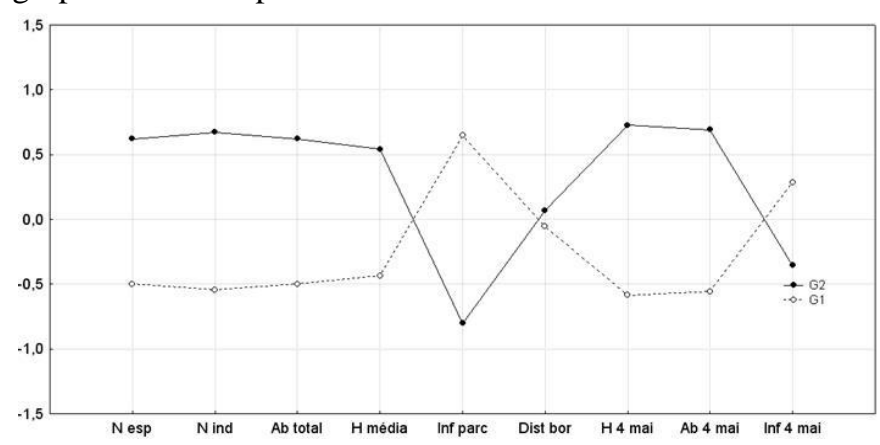

Parcelas com maior de infestação por plantas invasoras apresentaram maior infestação por lianas nas quatro maiores árvores e estavam localizadas mais próximas da borda do fragmento. Elas também apresentaram menor área basal e altura média das árvores, menor número de indivíduos e número de espécies por hectare na parcela.

Observa-se na Figura 3 que as parcelas do grupo 1 encontram-se alojadas mais a esquerda em CP1 e as parcelas do grupo 2 estão alojadas mais a direita. A partir dos dois primeiros componentes principais foi construído o gráfico biplot com 58,42\% (CP1 42,97\% e CP2 15,45\%) da informação contida nas variáveis (dados padronizados).

A Análise de componentes principais é concordante com o k-means e com os resultados das análises anteriores uma vez que o grupo G2 ficou separado do Grupo G1 (Figura 3).

Figura 3 Gráfico bidimensional dos componentes principais 1 e 2 mostrando as distribuições das parcelas (G1 e G2) e das características da vegetação.

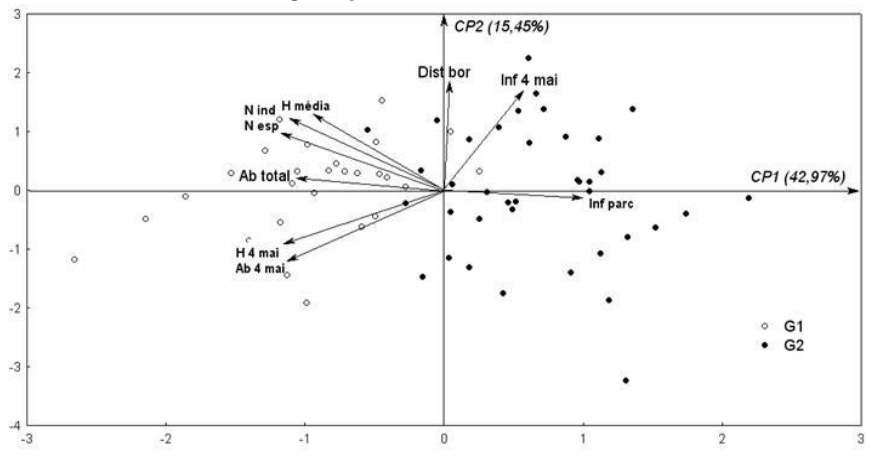

No primeiro componente as variáveis com maior poder discriminatório foram nessa ordem: altura média da quatro maiores árvores, número de indivíduos na parcela, área basal total, infestação da parcela, número de espécies por parcela, área basal da quatro maiores árvores e altura media dos indivíduos da parcela. No segundo componente principal as variáveis com maior poder discriminatório foram distanciamento da borda e infestação das quatro maiores árvores (Tabela 4).

Quanto ao primeiro componente principal (CP1), as variáveis referentes à infestação de parcela e das quatro maiores árvores (correlações positivas) contrastam com as variáveis número de espécies e indivíduos na parcela, área basal e altura média das parcelas e das quatro maiores árvores que apresentam correlações negativas e estão associadas.

Quanto ao segundo componente principal (CP2) pode-se destacar a associação das variáveis: distância da borda, infestação das quatro maiores árvores, altura média da parcela todas com correlações positivas. Essas variáveis contrastam com a área basal e altura das quatro maiores árvores e infestação da parcela que apresentam correlações negativas.

A variável distância da borda não discriminou grupos na análise K-médias mas, teve poder discriminatório entre parcelas. 
Tabela 4. Correlação entre cada característica de vegetação e um componente principal onde $\mathrm{N}$ esp = número de espécie por parcela, Nind = indivíduos por parcela, $\mathrm{Ab}$ total $=$ área basal total parcela, $\mathrm{H}$ média $=$ altura média de todos indivíduos por parcela, Inf parc = infestação por parcela, Dist bord = distância da parcela da borda, $\mathrm{H} 4$ mai = altura média das 4 maiores árvores da parcela, Ab 4 mai = área basal das quatro maiores árvores da parcela, Inf 4 mai = infestação média das quatro maiores árvores.

\begin{tabular}{lcc}
\hline CARACTERISTICA & $C P 1$ & $C P 2$ \\
\hline N espécie & $-0,71$ & 0,30 \\
N indi & $-0,76$ & 0,28 \\
Ab total & $-0,74$ & 0,02 \\
H média & $-0,66$ & 0,37 \\
Inf parc & 0,74 & $-0,06$ \\
Dist bor & 0,00 & 0,68 \\
H 4 mai & $-0,80$ & $-0,33$ \\
Ab 4 mai & $-0,69$ & $-0,34$ \\
Inf 4 mai & 0,36 & 0,63 \\
\hline
\end{tabular}

\section{CONCLUSÕES}

O uso combinado de técnicas multivariadas, como agrupamento hierárquico, k-médias e componentes principais permitiram caracterizar grupos de parcelas de similaridade de vegetação, o que revela a existência de um mosaico resultante da sucessão secundária em clareiras no interior dos fragmentos, além do efeito de borda nas áreas marginais.

As variáveis com maior poder de discriminação de grupos de parcelas foram em ordem decrescente: altura das quatro maiores árvores, número de indivíduos por parcelas, área basal total, infestação por parcelas, número de espécies, área basal das quatro maiores árvores e altura média das árvores como também estavam mais próximas da borda e apresentaram menor área basal e altura média das árvores, menor número de indivíduos e número de espécies por hectare na parcela.

Variáveis como altura média e área basal das árvores, número de indivíduos e número de espécies da parcela estãomais fortemente associadas às parcelas que apresentam menor porcentagem de parcelas sob efeito de borda.

\section{CONSIDERAÇÕES FINAIS}

A preservação do bioma Mata Atlântica, que antes ocupava mais de $80 \%$ da área de vegetação nativa do Estado de São Paulo é de grande importância, uma vez que ele detém um patrimônio biológico inigualável. A fragmentação desse bioma, em decorrência do uso indiscriminado, resultou em pequenos remanescentes de ecossistemas de forma isolada sob forte efeito de borda. Isso comprometeu a preservação desses ecossistemas, incluindo a flora e fauna típicas do bioma, muitas delas endêmicas.

A Floresta Tropical Estacional Semidecidual, uma das formações típicas desse bioma, tem sua sustentabilidade ainda mais comprometida uma vez que ocorre em locais de solos férteis que sofrem constantemente pressão com a expansão agrícola.
Essas florestas tropicais possuem uma diversidade de espécies com alto índice de endemismo e grande diversidade regional condicionada por fatores do meio como solo, clima, relevo. Esses fragmentos ainda sofrem uma ação antrópica que pode agravar ainda mais o grau de perturbação.

Para o trabalho de recuperação e conservação dessas áreas, uma base científica de dados referentes à estrutura e composição das florestas em estudo é primordial, bem como a análise dos fatores que condicionam a ocorrência das espécies.

No município de Pindorama, a Reserva Biológica de Pindorama, com 120 ha, pertencente ao Estado de São Paulo e localizada no Polo Regional de Desenvolvimento Tecnológico do Centro Norte é composta por quatro fragmentos de Floresta Tropical Estacional Semidecidual e que estão inseridos numa matriz agrícola com intensas atividades, muitas vezes agressivas, que podem comprometer a existência e manutenção desses fragmentos.

O presente trabalho vem contribuir com os trabalhos de preservação dos fragmentos da Reserva Biológica, uma vez que identifica as espécies arbóreas de ocorrência, determina os descritores fitossociológicos, analisa os atributos físicos e químicos do solo e caracteriza dois desses fragmentos com o uso de análise estatística multivariada.

Com a avaliação dos dois fragmentos, distantes aproximadamente $800 \mathrm{~m}$, pode-se observar que existe uma grande similaridade de espécies arbóreas entre ambos.

Para a avaliação da correlação entre atributos de solos e espécies arbóreas foi feito o uso combinado de técnicas multivariadas, como agrupamento hierárquico, k-médias e componentes principais que permitiram caracterizar grupos de parcelas de similaridade de vegetação, ressaltando essa técnica como importante ferramenta para caracterização de florestal.

Os resultados mostram que esses fragmentos estão sobre efeito de borda e apresentam sinais de degradação, como alta infestação de plantas invasoras, entre elas, gramíneas, arbustos e lianas. Projetos de recuperação e restauração de ecossistemas devem ser desenvolvidos na Reserva Biológica, como corredores ecológicos, reflorestamento no entorno dos fragmentos e enriquecimento de espécies arbóreas no interior dos mesmos, usando informações do presente trabalho.

\section{REFERÊNCIAS BILBIOGRÁFICAS}

BURGUER, D. Ordenamento florestal I. Curitiba: UFPR, 1974. 224 p.

COMISSÃO NACIONAL DE SOLOS. Levantamento de reconhecimento dos solos do Estado de São Paulo. Rio de janeiro: Serviço Nacional de Pesquisas Agronômicas (Boletim12), 634 p, 1960.

DURIGAN, G.; FRANCO, G. A. D. C.; SAITO, M.; BAITELO, J. B. Estrutura e diversidade do componente arbóreo da floresta na estação Ecológica de Cetetus, Gália, SP. Revista Brasileira de Botânica, São Paulo, v. 23 , p. 371-383, 2000

EMBRAPA (EMPRESA BRASILEIRA DE PESQUISA AGROPECUÁRIA). CENTRO NACIONAL DE PESQUISA DE SOLOS. Sistema brasileiro de 
classificação de solos. 2.ed. Rio de Janeiro: Embrapa Solos, 2006. 306p

HAIR, J. F.; ANDERSON, R. E.; TATHAM, R. L.; BLACK, W.; Análise Multivariada de dados. 5.ed. Porto Alegre: Bookman, 2005.

JARDIM, F.C.S.; SOUZA, A.L.; SILVA, A. F. Dinâmica da vegetação arbórea com DAP maior ou igual a 5,0 cm: comparação entre grupos funcionais e ecofisiológicos na estação experimental de silvicultura tropical do INPA, Manaus - AM. Revista Árvore, v. 20, n. 3, p.267-278, 1996.

LEITÃO FILHO, H.F. Considerações sobre a florística de florestas trópicas e subtropicais do Brasil. IPEF, n.45, p.41-46, 1987.

LEITÃO FILHO, H.F. Ecologia da mata atlântica em Cubatão. São Paulo: UNESP/UNICAMP, 1993. 184 p.

LEPSCH, I. F.; VALADARES, J. M. A. S. Levantamento pedológico detalhado da Estação Experimental de Pindorama. Bragantia, Campinas, v. 35, n. 40, p.1976.

LIMA-RIBEIRO, M. S. Efeitos de borda sobre a vegetação e estruturação populacional em fragmentos de Cerradão no Sudoeste Goiano, Brasil. Acta Botanica Brasilica, São Paulo. v. 22, n. 2, p. 535-545, 2008.

MUELlER-DOMBOIS, D.; ELLENBERG, H. Aims and methods of vegetation ecology. New York: Willey, 1974. 574 p.

NOBREGA, A. M. F.; VALERI, S. V.; PAULA, R. C.; SILVA, S. A.; RÊGO, N. H. Uso da fitossociologia na avaliação da efetividade de restauração florestal em uma várzea degradada do Rio Mogi Guaçu, SP. Scientia Forestalis, Piracicaba, n. 75, p. 51-63, 2007.

RAIJ, B.V.; QUAGGIO, J. A.; FURLANI, A. M. C. Recomendações de adubação e calagem para o Estado de São Paulo. 2. ed. Campinas: IAC, 1996. 285p.

SWAINE, M.D.; WHITMORE, T.C. On the definition of ecological species groups in tropical rain forests. Vegetatio, v. 75, p. 81-86, 1988.

TABANEZ, A. A. J.; VIANA, V. M.; DIAS, A. S. Conseqüiências da fragmentação e do efeito de borda sobre a estrutura, diversidade e sustentabilidade de um fragmento de floresta de planalto de Piracicaba, SP. Revista Brasileira de Biologia, São Carlos, n. 57, v. 1, p. 47-60, 1997.

TABARELLI, M.; MONTOVANI, W. Clareiras naturais e a riqueza de espécies pioneiras em uma floresta atlântica Montana. São Paulo (SP). Revista Brasileira de Botânica, São Paulo, v. 59, n. 2, p. 251-261, 1999.

VALERI, S. V.; POLITANO, W.; SENÔ, K. C. A.; BARRETO, A. L. N. M. Manejo e recuperação florestal legislação, uso da água e sistema agroflorestais. Jaboticabal: FUNEP, 2003. v. 1, 180 p.

VIANA, V. M. Biologia e manejo de fragmentos de florestas naturais. Congresso Florestal Brasileiro, Sociedade Brasileira de Silvicultura e Sociedade Brasileira de Engenheiros Florestais, 6., 1990. Campos do Jordão. Anais... 155 p. 